mercado-para-os-produtos-organicos-esta-aquecido, $5 \mathrm{f} 48897 \mathrm{~d} 3 \mathrm{f} 94 \mathrm{e} 410 \mathrm{~V}$ gnVCM1000003b74010aRCRD>. Acesso em: 01 de maio de 2018.

WILKINSON, J. Distintos enfoques e debates sobre a produção familiar no meio rural. Rio de Janeiro. 2000.

\section{ANÁLISE TEMPORAL DA IMPLEMENTAÇÃO DO CADASTRO \\ AMBIENTAL RURAL NOS ASSENTAMENTOS RURAIS DO ESTADO DE MATO GROSSO}

Ana Luisa Araujo de Oliveira Vinicius de Freitas Silgueiro ${ }^{2}$ Weslei Butturi ${ }^{3}$

ReSUMo: O presente artigo tem o objetivo de realizar uma análise temporal da implementação do CAR dos assentamentos no estado de Mato Grosso, contemplando o histórico, os avanços e os desafios a serem superados atualmente. Os resultados evidenciam que ao longo do tempo, os entraves para a implementação desse instrumento foram de ordem jurídica e técnica, sendo que muitos esforços foram feitos ao longo de 2017 e 2018 para a construção de soluções que comtemplem a regularização ambiental dos assentamentos. Entre os avanços, destaca-se que o impasse jurídico em relação aos diferentes entendimentos de artigos do Código Florestal foi resolvido, contribuições técnicas para a criação de uma interface para os assentamentos no Sistema Mato-grossense de Cadastro Ambiental Rural (SIMCAR) foram entregues à Secretaria de Estado de Meio Ambiente de Mato Grosso (SEMA/MT) e ao Ministério Público Federal (MPF), assim como foi assinado um Acordo de Cooperação Técnica (ACT) entre a SEMAe o Instituto Nacional de Colonização e Reforma Agrária (INCRA) cujo objeto é justamente a regularização ambiental dos assentamentos. Sobretudo, há a necessidade de uma tomada de decisão da SEMA/MT e plano de trabalho claro para implementação das customizações necessárias ao SIMCAR. Somente após isso, os órgãos fundiários e assentados poderão cumprir com as responsabilidades atribuídas pelo Código Florestal para a regularização

'Doutoranda no Programa de Pós Graduação em Desenvolvimento Rural da Universidade Federal do Rio Grande do Sul (PGDR/UFRGS). E-mail:aluisamt@gmail.com

${ }^{2}$ Especialização em Gest. Int. Sist. Socioeco. Prod. Fam. Amz. Legal pela Universidade do Estado de Mato Grosso, Brasil(2015).Coordenador do Núcleo de Geotecnologias do Instituto Centro de Vida , Brasil. E-mail: vinicius.silgueiro@icv.org.br

${ }^{3}$ Esp. Eng. Florestal, Analista de Geotecnologias do Instituto Centro de Vida (ICV), Alta Floresta, MT, Brasil. E-mail: weslei.butturi@icv.org.br 
ambiental dos assentamentos rurais. Caso essa decisão não seja tomada, a situação de irregularidade ambiental dos assentamentos rurais pode ficar ainda mais delicada, uma vez que o prazo para a inscrição no CAR é 31 de dezembro de 2018

Palavras Chave: Código Florestal; Regularização Ambiental; Instrumentos de gestão ambiental; Assentamentos de reforma agrária.

ABSTRACT: The present article has the objective of conducting a temporal analysis of the implementation of the CAR of the settlements in the state of Mato Grosso, contemplating the history, the advances and the challenges to be overcome today. The results show that, over time, the obstacles to the implementation of this instrument were legal and technical, and many efforts were made during 2017 and 2018 to construct solutions that contemplate the environmental regularization of settlements. Among the advances, it is highlighted that the legal impasse in relation to the different understandings of articles of the Forest Code was solved, technical contributions for the creation of an interface for the settlements in the Mato Grosso System of Rural Environmental Register (SIMCAR) were delivered to the Environmental State Agency (SEMA/MT) and the Federal Public Prosecutor (MPF), as well as a Technical Cooperation Agreement (ACT) between SEMA and the National Institute of Colonization and Agrarian Reform (INCRA) whose object is precisely the environmental regularization of settlements. Above all, there is a need for SEMA/MT decision making and a clear work plan for implementing the necessary customizations to SIMCAR. Only after that, the land and seated agencies can fulfill the responsibilities assigned by the Forest Code for the environmental regularization of rural settlements. If this decision is not taken, the situation of environmental irregularity in rural settlements may become even more delicate, since the deadline for enrollment in the CAR is December 31, 2018.

Keywords: Forest Code; Environmental Regulation; Environmental management instruments; Agrarian reform settlements.

\section{INTRODUÇÃo}

Os assentamentos rurais são ambientes estratégicos para o desenvolvimento rural e se constituem em modelos de integração da população, num contexto de redistribuição da propriedade fundiária
(BERGAMASCO et al., 1997), contribuindo para produção de alimentos, geração de empregos e melhoria da renda para as famílias assentadas, bem como para a economia dos municípios em que foram criados.

No entanto, apesar da importância atribuída aos assentamentos, em Mato Grosso, a regularização ambiental dessas áreas encontra-se comprometida pela falta de implementação e desenvolvimento dos instrumentos que atendem as necessidades desses espaços rurais, a começar pelo Cadastro Ambiental Rural (CAR).

O estado de Mato Grosso é pioneiro (Lei Complementar Estadual 343/2008) na criação e implementação do CAR. Esse instrumento de gestão ambiental integra a Política Estadual de Meio Ambiente desde o ano de 2008, como parte do Programa MT Legal e foi implementado pelo Sistema Integrado de Monitoramento e Licenciamento Ambiental de Mato Grosso (SIMLAM) ${ }^{4}$, onde posseiros e proprietários rurais faziam a inscrição no CAR, inclusive os assentados de reforma agrária.

Em 2012, com a revisão do Código Florestal Brasileiro (Lei 12.651/2012), o CAR passou a ser instrumento obrigatório para todas as posses e propriedades rurais do país, e o Serviço Florestal Brasileiro (SFB) passou a gerenciar o desenvolvimento e implementação do Sistema Nacional de Cadastro Ambiental Rural (SICAR).

No sistema federal, a estratégia adotada pelo INCRA para o cadastramento dos assentamentos de reforma agrária foi a contratação de uma consultoria especializada da Universidade Federal de Lavras (UFLA) - desenvolvedora do SICAR - para fazer a inscrição no CAR. O método utilizado consistiu em realizar o cadastro em duas etapas: 1) inserir os perímetros totais dos assentamentos e vincular a relação de beneficiários (RB) aos mesmos e; 2) posteriormente, cadastrar as parcelas (lotes) vinculando cada ocupante ao seu respectivo lote.

Apesar de ter tomado a decisão em 2014 de migrar a base de dados do SIMLAM para o SICAR, em 2016, o Estado de Mato Grosso decidiu pela retomada da gestão do instrumento de cadastramento e iniciou a construção de um novo sistema, o Sistema Mato-grossense de Cadastro Ambiental Rural (SIMCAR).

Desde junho de 2017, quando o novo sistema entrou em operação e foi instituído pela Lei Complementar 592/2017 e pelo Decreto Estadual 1031/2014, este é o instrumento utilizado para a implementação do CAR e

$\overline{{ }^{4} \text { Mais informações do SIMLAM podem ser obtidas no link: https://monitoramento.sema.mt.gov.br/simlam/ }}$ 
Programa de Regularização Ambiental (PRA) no estado de Mato Grosso. Desde então, diversos marcos legais estaduais foram instituídos.

No entanto, apesar desse "vai-e-vem" na gestão dos instrumentos para a regularização ambiental das posses e propriedades rurais, o Estado não contemplou a situação dos assentamentos e seus respectivos lotes, de forma que os embargos permanecem e os agricultores familiares desses imóveis continuam em condição de irregularidade ambiental. Tal situação impede legalmente qualquer forma de uso e ocupação do solo e inviabiliza o acesso à crédito para produção agropecuária. Uma vez que, sem o CAR, não é possível obter a licença ambiental que autoriza o desenvolvimento das atividades agropecuárias e florestais.

Diante dessa situação, uma série de ações vem sendo desenvolvida com a finalidade de implementar os instrumentos do Código Florestal nas áreas de assentamentos de reforma agrária no estado de Mato Grosso. Dessa forma, o artigo tem o objetivo de realizar uma análise temporal da implementação do CAR dos assentamentos, contemplando o histórico, os avanços e os desafios a serem superados atualmente no estado.

Além dessa introdução, o artigo está dividido em mais três sessões: a primeira sessão apresenta a metodologia utilizada para a pesquisa; a segunda sessão traz os resultados subdivididos em três subseções, conforme a análise temporal realizada e; por fim, a terceira sessão apresenta as considerações finais.

\section{Metodologia}

O conhecimento sobre políticas públicas tem sido fundamental para a criação, implementação e avaliação das ações desenvolvidas pelas organizações governamentais e não governamentais nos espaços políticos. Nesse sentido, neste texto buscou-se utilizar elementos sobre a análise da implementação de políticas públicas para compreender em uma perspectiva temporal os marcos legais instituídos com o objetivo de implementar o CAR nos assentamentos rurais. Também foram consideradas variáveis locais e burocracias implementadoras do estado de Mato Grosso.

Além disso, para essa pesquisa foram utilizadas fontes de dados secundários, a partir da análise documental de textos de leis, decretos, relatórios de reuniões, documentos técnicos emitidos pelos atores sociais envolvidos no processo de regularização ambiental dos assentamentos de Mato Grosso, assim como fontes primárias a partir do relato de pessoas que participaram desse processo e bases de dados.

\section{RESULTADOS E DISCUSSões}

Para melhor contextualizar a implementação dos instrumentos do Código Florestal e efetivação da regularização ambiental dos assentamentos de reforma agrária no estado de Mato Grosso, os resultados da pesquisa foram divididos em três subseções, conforme o Mapa 01.

Mapa 01 - Imóveis inscritos no Cadastro Ambiental Rural em Mato Grosso, de acordo com o sistema de cadastramento vigente.

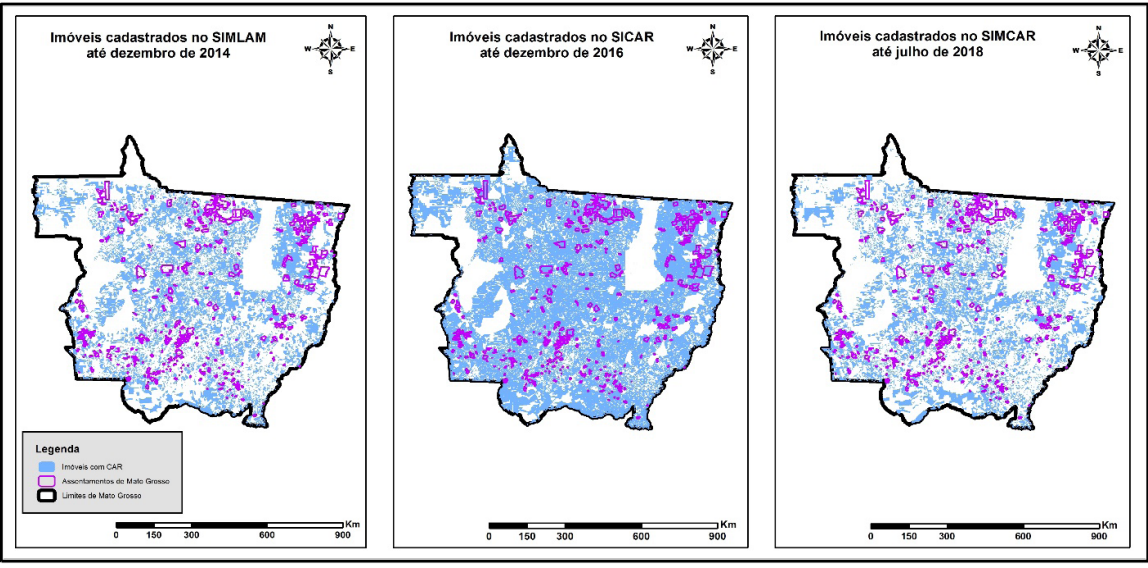

Fonte: Instituto Centro de Vida (2018)

A primeira subseção apresenta os resultados do período em que a regularização ambiental no estado ocorria pelo Programa MT Legal entre os anos de 2008 e 2014. A segunda, traz os resultados da regularização ambiental após a revisão do Código Florestal, de 2012 a maio de 2017, enquanto o estado utilizou o sistema federal (SICAR) como instrumento para a regularização ambiental das posses e propriedades rurais mato-grossenses e a terceira apresenta os resultados referente ao período após maio de 2017 até os dias atuais, em que o Estado vem implementando o Código Florestal a partir de um instrumento técnico com gestão própria (SIMCAR).

REgularização aMbiental No PROGRAMA MT LEgal (2008 a 2014)

O uso e a ocupação do solo no estado de Mato Grosso têm sido intensificados nos últimos anos, sobretudo após a década de 1970 em função das políticas de integração nacional, que objetivavam incorporar os grandes "vazios demográficos" ao processo produtivo brasileiro, expandindo a fronteira agrícola nacional.

Apesar de haver uma legislação ambiental vigente naquele período , pouco ou nada foi considerado nessa expansão e o uso dos recursos naturais 
foi "quase uma condicionante" para o desenvolvimento da agropecuária em Mato Grosso. Com a instituição da Lei de Crimes Ambientais em 1998 (Lei $n^{\circ} 9.605 / 1998$ ), muitos produtores passaram a desenvolver suas atividades à margem da lei e foram "punidos" pelos crimes ambientais cometidos, seja pelo desmatamento ilegal cometido e/ou pela ausência de licença para desenvolver as atividades.

Na perspectiva de regularização das posses e propriedades rurais, em 2008, o Estado de Mato Grosso criou na Lei Complementar estadual 343/2008 o "Programa Mato-grossense de Legalização Ambiental Rural - MT Legal com o objetivo de promover a regularização das propriedades e posses rurais do estado e sua inserção no Sistema de Cadastramento Ambiental Rural elou Licenciamento Ambiental de Propriedades Rurais - SLAPR". Para a implementação dessa política pública, em 2009, passou a funcionar o Sistema Integrado de Monitoramento e Licenciamento Ambiental de Mato Grosso (SIMLAM), do qual o Cadastro Ambiental Rural (CAR) era uma parte integrante, juntamente com a Licença Ambiental Única (LAU).

Entre os anos de 2009 e 2014, no SIMLAM foram realizados o CAR e/ou a LAU de aproximadamente 43 mil posses e propriedades rurais, inclusive alguns lotes de assentamentos de reforma agrária. Nesse sistema os assentados podiam fazer o cadastro de suas terras com o auxílio de um responsável técnico contratado e credenciado pelo Conselho Regional de Engenharia e Agronomia de Mato Grosso (CREA/MT).

Figura 01 - Perspectiva temporal dos principais acontecimentos na regularização ambiental de posses e propriedades rurais no estado de Mato Grosso, entre os anos de 2008 e 2014.

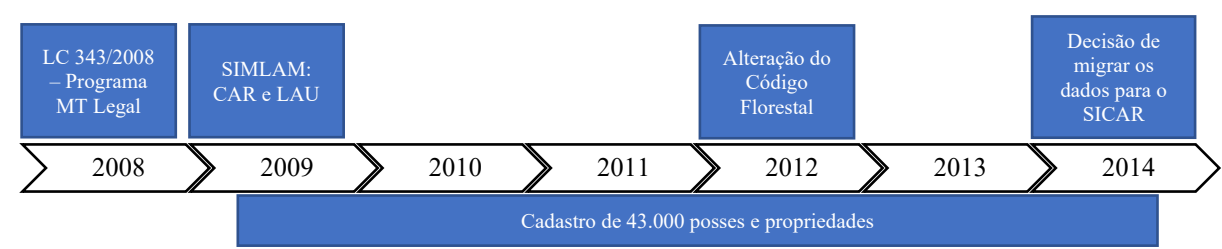

Fonte: A pesquisa.

Conforme visto na Figura 01, em 2012 houve a revisão do Código Florestal brasileiro (Lei 12.651/2012) e um novo momento para a regularização ambiental das posses e propriedades mato-grossenses se inicia.
REgUlarizaÇão ambiental APÓS A REVISÃo do Código FloRestal, NO SICAR (2014 A MAIO/2017)

Com a revisão do Código Florestal em 2012, o CAR passou a ser instrumento integrante da política pública federal e a inscrição das posses e propriedades rurais passou a ser obrigatória em todo o país. Foi instituído o Sistema Nacional de Cadastro Ambiental Rural (SICAR) e o Serviço Florestal Brasileiro (SFB) passou a gerenciar o desenvolvimento e implementação do instrumento.

O SICAR foi criado pelo Decreto Federal ${ }^{\circ} 7.830 / 2012$ e definido como um "sistema eletrônico de âmbito nacional destinado ao gerenciamento de informações ambientais dos imóveis rurais", de modo que, os estados que possuíam ou optaram por construir sistemas próprios com gestão estadual, deveriam integrar-se ao sistema nacional. Em 2014, quando o SICAR foi oficialmente instituído e passou a receber inscrições do CAR, o Estado de Mato Grosso optou por aderir a esse sistema federal e migrar sua base de dados dos imóveis cadastrados para o mesmo.

Diferente do Programa MT Legal, pelo Código Florestal a responsabilidade para a inscrição dos assentamentos de reforma agrária no CAR passou a ser dos órgãos fundiários, sendo, o INCRA para os assentamentos federais e o Instituto de Terras do Estado de Mato Grosso (INTERMAT) para os assentamentos estaduais. Como dito anteriormente, por meio de um convênio com a Universidade Federal de Lavras (UFLA), o INCRA construiu um módulo de cadastramento próprio para assentamentos e realizou a inscrição do perímetro de todos os assentamentos federais do país entre os anos de 2014 e 2016, no que ficou conhecido como "Módulo de CAR Perímetro". No entanto, por falta de recursos humanos e financeiros no INTERMAT, o cadastro dos assentamentos estaduais não avançou no SICAR.

No CAR do perímetro dos assentamentos do INCRA foram apresentadas a situação de cobertura do solo e hidrografia, assim como anexadas as relações de beneficiários (RBs) ativas de cada assentamento. De forma geral, o assentado que tinha o nome listado na relação de beneficiários estava com sua regularização ambiental em andamento. No entanto, a situação ambiental de cada lote não era possível de ser conhecida, assim como não era possível fazer a responsabilização individual por danos ambientais dentro dos lotes, o que se configurou como um entrave para seguir com a regularização ambiental e suspensão dos embargos nos assentamentos.

Após o Módulo de CAR Perímetro, e ainda em fase de teste, a parceria INCRA-UFLA desenvolveu um módulo para o cadastro dos lotes de assentamentos, o "Módulo de CAR Lote", o qual individualiza o CAR, 
criando condições para a responsabilização por danos ambientais e pela preservação e recomposição da vegetação nativa e demais recursos naturais.

Em 2016, no SICAR havia 66.935 imóveis rurais inscritos de até 4 módulos fiscais $(5.742 .728,47$ ha), 383 perímetros de assentamentos (total de 4.305.590,71 ha - 69.119 lotes) e nenhuma comunidade tradicional (OLIVEIRA; THUAULT; BUTTURI, 2017). Assim como, 27.689 imóveis com mais de 4 módulos fiscais (55.913.956,55 hectares).

Porém, apesar de estar clara na legislação a responsabilidade do poder público com as etapas de regularização ambiental para agricultura familiar, incluindo os assentamentos rurais, passados mais de seis anos da revisão do Código Florestal, graves lacunas de coordenação de esforços entre os órgãos públicos responsáveis foram diagnosticadas e ainda não resolvidas (OLIVEIRA; THUAULT; BUTTURI, 2017). Como consequência, a implementação e desenvolvimento dos instrumentos para a regularização ambiental dos imóveis da agricultura familiar pouco evoluíram e, em 2016, Mato Grosso iniciou a análise dos cadastros que encontravam-se no SICAR

Ainda em 2016, dois anos após a decisão de migrar os dados para o SICAR e utilizá-lo como sistema de cadastramento dos imóveis matogrossenses, o Estado de Mato Grosso, alegando insatisfação técnica com o sistema federal, necessidade de voltar a ter a gestão do instrumento e maior autonomia, decidiu por desenvolver um novo sistema estadual, fazendo a migração de todos os cadastros realizados no SICAR para o Sistema Matogrossense de Cadastro Ambiental Rural (SIMCAR).

A Figura 02 ilustra os principais acontecimentos na legislação e resultados obtidos após a alteração do Código Florestal no âmbito do SICAR.

Figura 02 - Perspectiva temporal dos principais acontecimentos na regularização ambiental de posses e propriedades rurais no estado de Mato Grosso após a alteração do Código Florestal, entre os anos de 2012 e 2016.

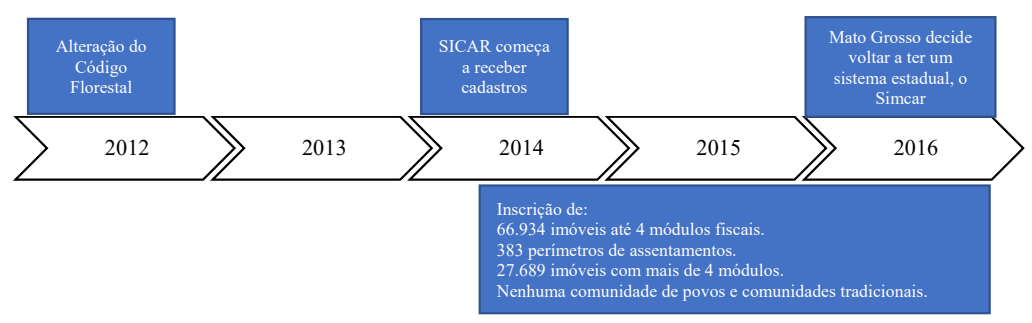

Fonte: A pesquisa.
RegularizaÇão ambiental APóS A REVISÃo do Código FloRestal, NO SIMCAR (JUNHO/2017 ATÉ O MOMENTO)

O desenvolvimento do SIMCAR levou alguns meses e, em junho de 2017, os proprietários e posseiros rurais de Mato Grosso puderam começar a utilizar o novo sistema, instituído pela Lei Complementar (LC) estadual $n^{\circ} 592 / 2017$, que revogou a LC 343/2008 (que havia criado o Programa MT Legal) e foi regulamentada pelo Decreto 1.031/2017.

No entanto, no processo de migração dos mais de 113 mil cadastros inscritos no SICAR, para o SIMCAR, os cadastros dos 383 perímetros dos assentamentos não foram migrados, colocando esses assentamentos e seus moradores à margem do primeiro passo da regularização ambiental e inviabilizando o acesso a um recibo do CAR válido para fins de continuidade da regularização ambiental e/ou acesso a outras políticas públicas (por exemplo, crédito). É importante destacar que, no Sistema de Informações de Projetos de Reforma Agrária (SIPRA) do INCRA, há 549 assentamentos cadastrados no estado de Mato Grosso e, desses, 154 possuem embargos por desmatamento, o que representa $28 \%$ do total de assentamentos e $52 \%$ da área total dos assentamentos dessa unidade da federação (OLIVEIRA; THUAULT; BUTTURI, 2017).

Além desse cenário de irregularidade ambiental em que os assentamentos estão colocados por uma questão técnica do SIMCAR não atender suas necessidades, a regulamentação do Decreto Estadual 1.031/2017 deu visibilidade a um impasse jurídico em relação aos diferentes entendimentos de artigos do Código Florestal. Diante disso, o entendimento ao longo de 2017 e 2018 é de que as soluções dos entraves para a regularização ambiental dos assentamentos de reforma agrária deveriam ser de ordem técnica e jurídica. Ou seja, se de um lado o instrumento técnico do SIMCAR não atende as particularidades desses imóveis rurais, por outro lado, o que estava regulamentado também não proporcionava segurança jurídica ao processo.

Dessa forma, optou-se por organizar essa sessão em subseções, dando destaque ao entraves e soluções de aspectos jurídicos dos marcos regulatórios e de aspectos técnicos do SIMCAR.

\section{ASPECTOS JURÍDICOS DOS MARCOS REGULATÓRIOS}

Como mencionado, o Decreto 1.031/2017, que regulamenta o SIMCAR, trouxe algo novo (e ao mesmo tempo contraditório ao Código Florestal) ao afirmar no artigo 13 que, para efeitos de área de reserva legal (ARL), não seria aplicado o disposto no artigo 67 da Lei Federal no ${ }^{\circ} 12.651 / 2012$. Este 
artigo instituiu um marco temporal ao determinar que, a ARL em imóveis rurais com até 04 módulos fiscais, cujo percentual de vegetação nativa era inferior ao exigido por lei em 22 de julho de 2008, passou a ser constituída pela área ocupada com vegetação nativa existente naquela data, proibindo novas conversões para uso alternativo do solo nessas propriedades.

Quais as implicações disso? Ao não considerar o artigo 67 para os assentamentos rurais, o Estado de Mato Grosso passou a considerar esses imóveis, para fins do CAR, como grandes propriedades rurais, uma vez que o perímetro médio deles no estado é de 10.334 hectares. Além disso, de acordo com o Decreto 1.031/2017 "se a inscrição do lote se der em momento anterior a inscrição do Projeto de Assentamento na base de dados do SIMCAR, aquele deverá suportar dentro de sua parcela a área de reserva legal correspondente a extensão da posse rural, de acordo com a tipologia". Essa regulamentação estadual significou um entrave jurídico ao que já estava preconizado no Código Florestal.

Tendo em vista a divergência na interpretação e aplicação de artigos da lei federal, que tratam da regularização de passivos ambientais, aos projetos de assentamento do INCRA de Mato Grosso, em 2017 o Ministério Público Federal (MPF) realizou diversas reuniões com a presença da SEMA/MT, INCRA, IBAMA e Ministério Público Estadual (MPE), para discutir a regularização dos passivos ambientais dessas áreas.

Ainda em 2017, uma audiência pública realizada na Assembleia Legislativa do Estado de Mato Grosso (ALMT) teve o objetivo de ouvir as dificuldades dos agricultores familiares em relação as atuais legislações estadual e federal que orientam a regularização ambiental. Esse evento, contou com a participação e pronunciamentos de diversos órgãos governamentais (SEMA, IBAMA, INCRA, EMPAER, INTERMAT, Banco do Brasil, MPE), além de entidades representativas (FETAGRI, SINTERP, STTRs, Cooperativas e Associações dos agricultores familiares) e organizações que trabalham com assentamentos (ICV, Projeto RADIS-FINATEC/UNB, FASE e IPAM).

A partir do depoimento desses atores sociais, ficou evidente a dificuldade dos agricultores familiares mato-grossenses, principalmente aqueles residentes em assentamentos rurais, no acesso a outras políticas públicas pela ausência do CAR (com destaque para crédito e licença para o desenvolvimento da atividade produtiva, que no caso especifico de Mato Grosso vigora até 31/12/2018 a Autorização Provisória de Funcionamento da Atividade Rural - APF). Essa situação contribui para criar um cenário de insegurança ambiental e inviabilização do desenvolvimento rural nas propriedades desse grupo social, uma vez que ficam travadas ações para acesso à crédito de custeio e investimento, assim como a falta da licença impede o uso e ocupação do solo em conformidade com as normas ambientais vigentes. Nesse sentido, o encaminhamento da audiência pública foi a criação de um GT interinstitucional com a perspectiva de propor soluções junto aos órgãos responsáveis.

Dessa forma, paralelamente às reuniões que ocorreram ao longo de 2017 mediadas pelo MPF, o GT resultante da audiência pública realizada na ALMT também se reuniu, e tiveram êxito na publicação do Decreto Estadual $\mathrm{n}^{\circ} 1.211$ em outubro de 2017, que alterou o Decreto $\mathrm{n}^{\circ} 230$ de agosto de 2015, isentando a apresentação da APF até 31/12/2018 aos agricultores que estão inscritos no CAR.

Como resultado das reuniões mediadas pelo MPF, em março de 2018, o Ministério Público Federal (MPF) emitiu nota recomendatória ao estado de Mato Grosso para a revogação do parágrafo $3^{\circ}$, do artigo 13 do Decreto Estadual $\mathrm{n}^{\circ} 1.031 / 2017$, para que fosse aplicado a definição de área de reserva legal consolidada, nos termos do artigo 67 do Código Florestal, em favor dos assentamentos rurais, desde que a publicação da portaria que cria o projeto de assentamento seja anterior a 22 de julho de 2008. Ou seja, para os assentamentos criados antes de 22 de julho de 2008 o Estado aplica o artigo 67, já para os assentamentos criados após 22 de julho de 2008, o percentual de ARLé o determinado pelo artigo 12 do Código Florestal $(80 \%$ no Bioma Amazônia, 35\% no cerrado e 20\% nas demais regiões).

Após nota recomendatória do MPF, o governo de Mato Grosso incorporou no Decreto Estadual 1.491, de 15 de maio de 2018, a recomendação de interpretar os assentamentos e seus lotes como imóveis da agricultura familiar, conforme é disposto na Lei Federal da Agricultura Familiar (Lei n ${ }^{\circ}$ 11.326/2006). A publicação desse marco regulatório significou um avanço para a solução jurídica da situação. E, uma vez superadas as divergências de interpretação e aplicação de artigos do Código Florestal, o passo seguinte seria construir a solução técnica no SIMCAR para que os cadastros de assentamentos pudessem ser efetivados no novo sistema estadual.

\section{ASPECTOS TÉCNICOS DO SIMCAR}

No que se refere aos aspectos técnicos, em janeiro de 2018, o INCRA sinalizou a assinatura de um Termo de Cooperação Técnica com o Instituto 
Centro de Vida (ICV), porém mesmo nos finalmente para sua formalização administrativa, o trabalho conjunto vem ocorrendo. Resultado disso, foi que em 11 de maio de 2018, as duas organizações protocolaram no MPF e compartilharam com a SEMA documento intitulado "Subsídios técnicos para o 'SIMCAR Assentamentos"'.

Nesse documento, INCRA e ICV apontaram uma série de considerações de ordem técnica para a customização de um módulo específico para a realização do CAR de assentamentos, em que, no ato do cadastro, sejam consideradas portaria de criação, perímetro total, parcelamento realizado pelo órgão fundiário e a relação de beneficiários por assentamento. Além da fase de cadastro, nesse documento, foi sugerido um fluxo de trabalho englobando também as fases de análise e validação do CAR dos assentamentos rurais de Mato Grosso, considerando suas especificidades de acordo com a modalidade (Projeto de Assentamento (PA), Projeto de Desenvolvimento Sustentável (PDS) e outras) e situação da reserva legal (individual, coletiva e mista - coletiva + individual).

Cabe destacar que essa trajetória para o cadastramento dos assentamentos rurais, ainda não está acompanhada pelo cadastramento dos povos e comunidades tradicionais. Se por um lado, há o entendimento de que esse grupo social poderia utilizar a mesma interface dos assentamentos, por outro, compreende-se que eles possuem particularidades que inviabilizam o uso da mesma interface, e, portanto, deveria ser construído um espaço próprio no SIMCAR. Além disso, pelo INCRA deverá ser inscrito no CAR apenas comunidades tituladas (que no caso de Mato Grosso, há apenas o Quilombo de Mata Cavalo), de forma que, as demais comunidades quilombolas e outros povos e comunidades tradicionais (extrativistas, retireiros do Araguaia, pescadores artesanais e ribeirinhos) continuam desassistidos da ação do Estado.

Em agosto de 2018, SEMA e INCRA assinaram Acordo de Cooperação Técnica (ACT) que tem como objeto o desenvolvimento de ações conjuntas destinadas à realização do CAR em projetos de assentamentos de reforma agrária e territórios quilombolas titulados no Estado de Mato Grosso. Com isso, são esperados avanços na construção da interface no SIMCAR para recepção, análise e validação dos cadastros dos assentamentos para se chegar ao CAR de cada lote, conhecimento do passivo ambiental de forma individual e promoção de ações para a suspensão dos embargos de lotes e assentamentos, se for o caso.

Além disso, também foi elaborada a minuta de uma Portaria (ainda não publicada) para formalizar a atuação do Grupo de Trabalho Interinstitucional sobre Regularização Ambiental em Áreas de Assentamentos Rurais no Estado de Mato Grosso, a partir dos Instrumentos de Cadastro Ambiental Rural (CAR) e Programa de Regularização Ambiental (PRA), do qual o ICV faz parte, e está colaborando com essa construção.

Figura 03 - Perspectiva temporal dos principais acontecimentos na regularização ambiental dos assentamentos rurais no estado de Mato Grosso após a alteração do Código Florestal, entre os anos de 2017 e 2018.

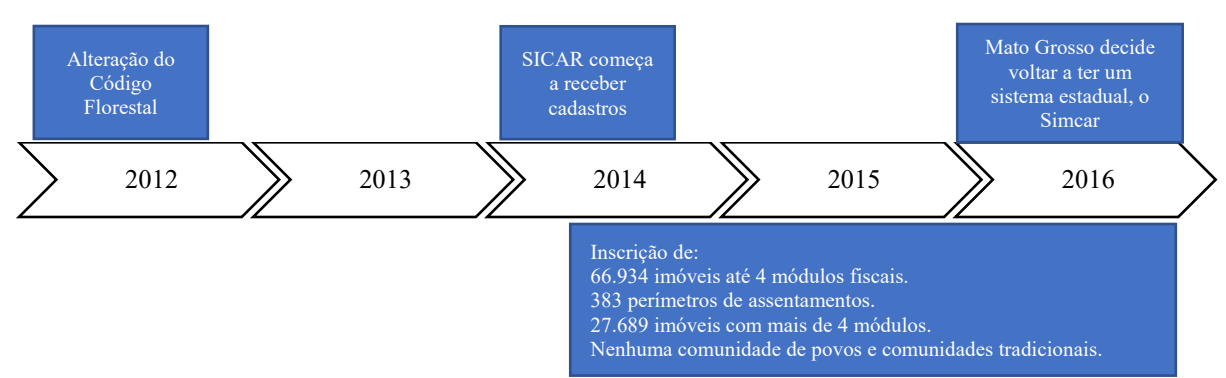

Fonte: A pesquisa.

Entre os meses de maio e agosto de 2018 este Grupo de Trabalho realizou diversas reuniões com o objetivo de contribuir com a interface no SIMCAR específica para receber os cadastros de assentamentos (Figura 03). No entanto, após a operação realizada na SEMA (em agosto) com o objetivo de apurar irregularidades na análise do CAR no estado, as reuniões do GT foram paralisadas. As discussões ainda estão no ponto de definir se para o cadastramento dos assentamentos o estado de Mato Grosso vai desenvolver uma interface própria no SIMCAR, ou se vai utilizar e integrar a esse sistema, o módulo de CAR lote do SICAR.

Porém, independentemente da decisão, demandará tempo para a implementação dessa solução técnica: se for utilizar o módulo de CAR lote do SICAR, precisará ser customizado para atender as particularidades do estado, além disso necessitará da disponibilização do código fonte pelo Serviço Florestal Brasileiro (SFB) e pelo INCRA. Se for desenvolver um novo módulo, precisa de diálogo entre SEMA e UFLA para repasse de experiências e conhecimento para agilizar o desenvolvimento.

Fato é que, assim que o SIMCAR estiver pronto para receber os 
cadastros dos assentamentos rurais, já foram eleitos pelo Grupo de Trabalho Interinstitucional três projetos para serem pilotos para a implementação do CAR: PA Terra de Viver (Claudia/MT), Assentamento do Crédito Fundiário Mangaval (Cáceres/MT) ${ }^{5}$ e PA São Pedro (Paranaíta/MT). Além disso, a solução que for criada para os assentamentos federais, necessariamente contemplará os assentamentos estaduais, cuja gestão é do INTERMAT, e que deve ser envolvido das reuniões do Grupo de Trabalho.

O INCRA, ICV e equipe do Projeto RADIS (UNB/ FINATEC) iniciaram o compartilhamento das bases de dados necessárias a elaboração do CAR dos assentamentos e, possuir o CAR de seu lote, conhecer e recuperar seu passivo ambiental, é um anseio dos assentados e assentadas do estado de Mato Grosso ${ }^{6}$.

No entanto, apesar dos avanços citados, o grande entrave atualmente é a SEMA disponibilizar um espaço específico para o cadastramento de assentamentos rurais no Sistema Mato-grossense de Cadastro Ambiental Rural (SIMCAR).

Importante destacar que o prazo para inscrição no CAR é 31 de dezembro de 2018 e, caso os assentamentos não sejam inseridos a tempo no SIMCAR, seus moradores seguirão em situação de irregularidade ambiental no estado de Mato Grosso. A não ser que esse prazo seja mais uma vez prorrogado.

\section{CONSIDERAÇõES FINAIS}

Ao longo da análise ficam evidentes os entraves de ordem jurídica e técnica para a implementação do CAR nos assentamentos rurais de Mato Grosso, assim como os muitos esforços, que diferentes organizações, têm feito para a regularização ambiental desses imóveis.

Essa mobilização conseguiu obter avanços na resolução do impasse jurídico em relação aos diferentes entendimentos de artigos do Código Florestal. Assim como, foram entregues à Secretaria de Estado de Meio Ambiente (SEMA/MT) e ao Ministério Público Federal (MPF) contribuições técnicas para a criação de uma interface para o cadastramento de assentamentos no Sistema Mato-grossense de Cadastro Ambiental Rural

${ }^{5}$ Essa modalidade de assentamentos é resultante do Programa Nacional de Crédito Fundiário (PNCF) em que o beneficiário adquire imóveis rurais por meio de financiamento com prazo de pagamento de até 25 anos. Em Mato Grosso o programa é operacionalizado em parceria com a Secretaria de Estado de Agricultura Familiar e Assuntos Fundiários (SEAF/MT) e muitos se assemelham aos assentamentos de reforma agrária federal e estadual por possuir as reservas legais coletivas.

${ }^{6}$ Mais detalhes podem ser acessados no link: https://www.icv.org.br/2018/04/06/encontro-discute-regularizacao${ }^{6}$ Mais detalhes podem
(SIMCAR) e, em agosto de 2018, foi assinado um Acordo de Cooperação Técnica (ACT) entre a SEMA e o INCRA cujo objeto é a regularização ambiental dos assentamentos.

No momento atual evidencia-se a necessidade de uma tomada de decisão por parte da SEMA e constituição de plano de trabalho claro que leve a implementação no SIMCAR das funcionalidades necessárias à inscrição, análise e validação do CAR dos lotes dos assentamentos, e sequencia ao Programa de Regularização Ambiental (PRA) para a efetiva regularização dos passivos ambientais.

Somente após isso, os órgãos fundiários e assentados poderão cumprir com as responsabilidades atribuídas pelo Código Florestal quanto aos assentamentos rurais. Caso essa decisão não seja tomada, a situação de irregularidade ambiental dos assentamentos rurais pode ficar ainda mais delicada, uma vez que o prazo para a inscrição no Cadastro Ambiental Rural é 31 de dezembro de 2018.

Destaca-se ainda que, na situação atual, diversas organizações estão mobilizadas, há uma seleção de assentamentos que serão piloto na inscrição quando o SIMCAR estiver pronto para receber esses cadastros, famílias assentadas estão mobilizadas e anseiam pelo CAR de seus lotes. Assim como, INCRA e organizações parceiras iniciaram o compartilhamento das bases de dados necessárias ao CAR dos assentamentos, que precisam da interface no SIMCAR para serem inseridas.

Um caminho possível para a efetiva regularização ambiental dessas áreas seria o MPF e MPE estabelecerem um prazo para que a SEMA, em cooperação com o INCRA, incorpore no SIMCAR a solução técnica necessária para a recepção do CAR de assentamentos, assim como de povos e comunidades tradicionais. Para isso, pode-se fortalecer e contar com a atuação do Grupo de Trabalho Interinstitucional sobre Regularização Ambiental em Áreas de Assentamentos Rurais no Estado de Mato Grosso.

\section{REFERÊNCIAS}

Bergamasco, S.; BLANC-PAMARD, C.; CHONCHOL, M. E. Por um atlas dos assentamentos brasileiros: espaços de pesquisa. Rio de Janeiro: DL/Brasil, 1997. 48p.

BRASIL. Lei n ${ }^{\circ} 12.651$, de 25 de maio de 2012. Dispõe sobre a proteção da vegetação nativa. Disponível em: http://www.planalto.gov.br/ccivil_03/_ 
ato2011-2014/2012/lei/112651.htm. Acesso em: 27 de agosto de 2018.

Decreto $\mathbf{n}^{\mathbf{0}}$ 7.830, de 17 de outubro de 2012: Dispõe sobre o Sistema de Cadastro Ambiental Rural, o Cadastro Ambiental Rural, estabelece normas de caráter geral aos Programas de Regularização Ambiental, de que trata a Lei no 12.651, de 25 de maio de 2012, e dá outras providências. Diário Oficial da União. Brasília, DF. Disponível em: $<$ http://www. planalto.gov.br/ccivil_03/_Ato2011-2014/2012/Decreto/D7830.htm>. Acesso em: 27 de agosto de 2018.

MATO GROSSO. Lei complementar 343, de 24 de dezembro de 2008. Cria o Programa Mato-grossense de Regularização Ambiental Rural - MT LEGAL, disciplina as etapas do Processo de Licenciamento Ambiental de Imóveis Rurais e dá outras providências. Disponível em: http://app1.sefaz. mt.gov.br/sistema/legislacao/LeiComplEstadual.nsf/ 9733ald3f5bblab$384256710004 \mathrm{~d} 4754 / 53 \mathrm{c} 375 \mathrm{c} 601 \mathrm{f} 136810425753 \mathrm{~d} 00718339$ ?OpenDocument. Acesso em: 27 de agosto de 2018.

Lei complementar 592, de 26 de maio de 2017. Dispõe sobre o Programa de Regularização Ambiental - PRA, disciplina o Cadastro Ambiental Rural - CAR, a Regularização Ambiental dos Imóveis Rurais e o Licenciamento Ambiental das Atividades poluidoras ou utilizadoras de recursos naturais, no âmbito do Estado de Mato Grosso, e dá outras providências. Disponível em: http://app1.sefaz.mt.gov. br/0425762E005567C5/9733A1D3F5BB1AB384256710004D4754/2934 486634343A9C8425812F005B9C6E. Acesso em: 27 de agosto de 2018.

Decreto 1.031, de 02 de junho de 2017. Regulamenta a Lei Complementar $\mathrm{n}^{\circ} 592$, de 26 de maio de 2017, no que tange o Programa de Regularização Ambiental, o Sistema Mato-grossense de Cadastro Ambiental - SIMCAR, a inscrição e análise do Cadastro Ambiental Rural. Disponível em: http://app1.sefaz.mt.gov.br/0325677500623408/7C7B6A9347C 50F $55032569140065 \mathrm{EBBF} / 950801 \mathrm{C} 5453562 \mathrm{~B}-$ 984258137006C104B . Acesso em: 27 de agosto de 2018.

Decreto 1.211, de 02 de outubro de 2017. Regulamenta o art. 31 da Lei Complementar $n^{\circ}$ 592, de 26 de maio de 2017, instituindo a Autorização Provisória de Funcionamento de Atividade Rural - APF, no âmbito do procedimento da Licença Ambiental Única, bem como a forma de comunicação dos atos administrativos da Secretaria de Estado de Meio Ambiente - SEMA, e dá outras providências. Disponível em: https:// www.legisweb.com.br/legislacao/?id=351000. Acesso em: 27 de agosto de 2018

Decreto 1.491, de 15 de maio de 2018. Regulamenta a Lei Complementar $\mathrm{n}^{\circ}$ 592, de 26 de maio de 2017, no tocante as formas de regularização ambiental nos imóveis rurais e altera dispositivos do Decreto $\mathrm{n}^{\mathrm{o}} 1031$ de 02 de Junho de 2017. Disponível em: http://app1.sefaz.mt.gov. br/0325677500623408/7C7B6A9347C50F55032569140065EBBF/ FDEFD14C19539CCE8425828F005A6FCC. Acesso em: 27 de agosto de 2018.

OLIVEIRA, A. L. A.; THUAULT, A.; BUTTURI, W. Agricultura familiar e regularização ambiental no estado de Mato Grosso. Série Transparência Florestal. $\mathrm{N}^{\circ} 7$, ano 5. Disponível em https://www.icv.org.br/ wp-content/uploads/2017/03/transp-N7-site-1.pdf. Acesso em: 27 de agosto de 2018. ado de Mato Grosso, e dá outras providências. Disponível em: http://app1.sefaz.mt.gov.br/0425762E005567C5/9733A1D3F5BB1AB384256710004D4754/2934486634343A9C8425812F005B9C6E. Acesso em: 27 de agosto de 2018. 